\title{
Blood pressure in black, white and Asian factory workers in Birmingham
}

J. K. CRUICKSHANK*

M.B., B.Sc., M.R.C.P.

\author{
L. T. BANNAN
}

M.B., B.Sc., M.R.C.P.I.

M. BEEVERS

S.R.N.
S. H. D. JACKSON $\dagger$

M.B., M.R.C.P.

D. G. BEEVERS

M.D., F.R.C.P.

V. L. OSBOURNE

A.A.M.S.

University Department of Medicine, Dudley Road Hospital, Birmingham B18 7QH

\section{Summary}

A screening survey was conducted among factory workers, aged 15-64 years, in Birmingham, England to investigate ethnic differences in blood pressure. One-thousand and forty-nine subjects (784 men, 265 women) were screened, representing $79 \%$ of the eligible population.

Mean systolic and diastolic blood pressures generally did not differ between men of black West Indian $(n=173)$, local white $(n=439)$ or Asian $(n=172)$ origin, when matched by 10-year age groups. Analysis of covariance using age as the covariate revealed that, overall, Asian men had significantly lower systolic but higher diastolic pressures than the other ethnic groups. The proportion of men arbitrarily defined as hypertensive $(>160 \mathrm{mmHg}$ systolic or $\$ 95$ diastolic or blood pressures below this figure whilst receiving antihypertensive therapy) was $26 \%$ of West Indians, $22 \%$ of whites and $17 \%$ of Asians, but these were not significantly different when age was accounted for.

Black West Indian women $(n=101)$ did have higher diastolic pressure than white women $(n=164)$, but this difference was dependent on body mass index. Overall, systolic pressures in women were not significantly different.

These findings differ from those consistently reported from the United States.

KEY WORDS: blood pressure, blacks, whites, Asians.

\section{Introduction}

Epidemiological studies in the United States have

Present address: *Central Middlesex Hospital, London; $+\mathrm{St}$ Bartholomew’s Hospital, London; $\ddagger$ Letterkenny General Hospital, Eire. consistently reported higher blood pressures in blackis compared with whites (Comstock, 1957; Cassel, 197 గु Stamler et al., 1975). This greater prevalence of hypertension is reflected in higher mortality rates from hypertension-related disease including stroke It is not known whether these higher blood pressures can be explained by environmental influences, in cluding social class or diet, or whether they are. caused by a genetic predisposition (Langford, $1981 \%$ There have been very few population studies iff Britain which have compared the blood pressures of blacks and whites, and there is little data on people born in the Indian sub-continent. Marmot, Adelstei and Bulusu (1981) reported deaths due to hyperterf sion in Britain to be commoner in Afro-Caribbean than in the European-born population, and Cruickshank et al. (1980) found excess strokes in blacks, buf fewer heart attacks. By contrast, Asians had slightly more heart disease than whites (Pedoe et al., 1975) $\overrightarrow{0}$

To investigate the problem further, an epidemiological screening unit was established to examine bloo 9 pressures and other cardiovascular risk factors ib. factory workers in Birmingham. This is part of $\overline{2}$. multifactorial screening study, and the present papes presents data on blood pressures only.

\section{Methods}

The management of a group of factories ion Birmingham were asked to participate in a health survey of their employees. All factories were engaged in light industry but none had any known toxicologio cal hazard associated with cardio-pulmonary disease. In co-operation with the personnel departments an $\Phi$ Trade Unions, the entire workforce of each factoros was invited to complete a short standardized genera柿 health questionnaire, and attended a brief medicaf examination. Those not attending were counted fromp 
the factory payroll and the percent screened calculated.

The questionnaire included information on past and present cigarette and alcohol consumption, family and personal histories of vascular disease and drug therapy. Information was obtained on the country of birth, and type of occupation. The examination included measurement of height and weight (after removal of shoes or boots). The ethnic origin of the examinees was entered by the observers at the time of examination. People of obviously mixed descent who were difficult to classify as belonging to one ethnic group were screened but not included in this analysis. Only predominantly black (Caribbean), Asian (from Pakistan, India or Bangladesh) or white examinees were included. All but $2 \%$ of black and Asian subjects were born outside the United Kingdom. Blood pressure was measured in the right arm, half-way through and at the end of the questionnaire, using the random zero sphygmomanometer, with diastolic pressures taken at the fifth phase and with the subject seated. Sphygmomanometer cuffs were sized $12 \times 23 \mathrm{~cm}$; where necessary larger cuffs $(15 \times 34)$ were used when examining obese people. All the observers (the authors) were trained in use of the questionnaire and the sphygmomanometer. Only the first blood pressure measurements are considered in this report. Black employees who were not West Indian, and Asians not from the Indian subcontinent (mainly Yemeni arabs) are not included in this analysis, and as a total of only 20 Asian women were screened, this group is also excluded. Statistical analysis was conducted using the SPSS computer program.

\section{Results}

A total of 1079 factory workers in the above groups were examined, representing $79 \%$ of the eligible workforce in 12 Birmingham factories. The proportion eligible but who refused screening was approximately $20 \%$ in each ethnic group. One-thousand and forty-nine subjects (784 men, 265 women), aged 16-64 years, are considered in this paper.

Numbers of subjects screened and the overall prevalence of hypertension in each age, sex and ethnic sub-group are shown in Table 1 . In men, variations in prevalence of hypertension (greater or equal to $160 \mathrm{mmHg}$, systolic or $95 \mathrm{mmHg}$ diastolic or levels below these figures on treatment) between ethnic groups by age are not significantly different $\left(\chi^{2}=1 \cdot 13\right)$. Too few older Asians (55+ years) were seen for direct comparison, but differences in hypertension prevalence up to 55 years are not significant (Blacks v. Asians, aged 16-54 years, $\chi^{2}=1 \cdot 20$ ).

Among women, a total of $27 \%$ of West Indians are hypertensive compared with $16 \%$ of whites, $\left(\chi^{2}=5.43, P<0.05\right)$. However, the older black group is small and if ages 15-54 years are pooled and hypertension prevalence compared, the ethnic difference becomes significant $\left(\chi^{2}=9.76 ; 0.01>P>0.001\right)$.

Mean systolic and diastolic blood pressures were similar among men in each ethnic group (Fig. 1). Only 14 black men, aged 25-34 years, were screened,

TABLE 1. The prevalence of high blood pressure (HBP) in 1049 Birmingham factory workers

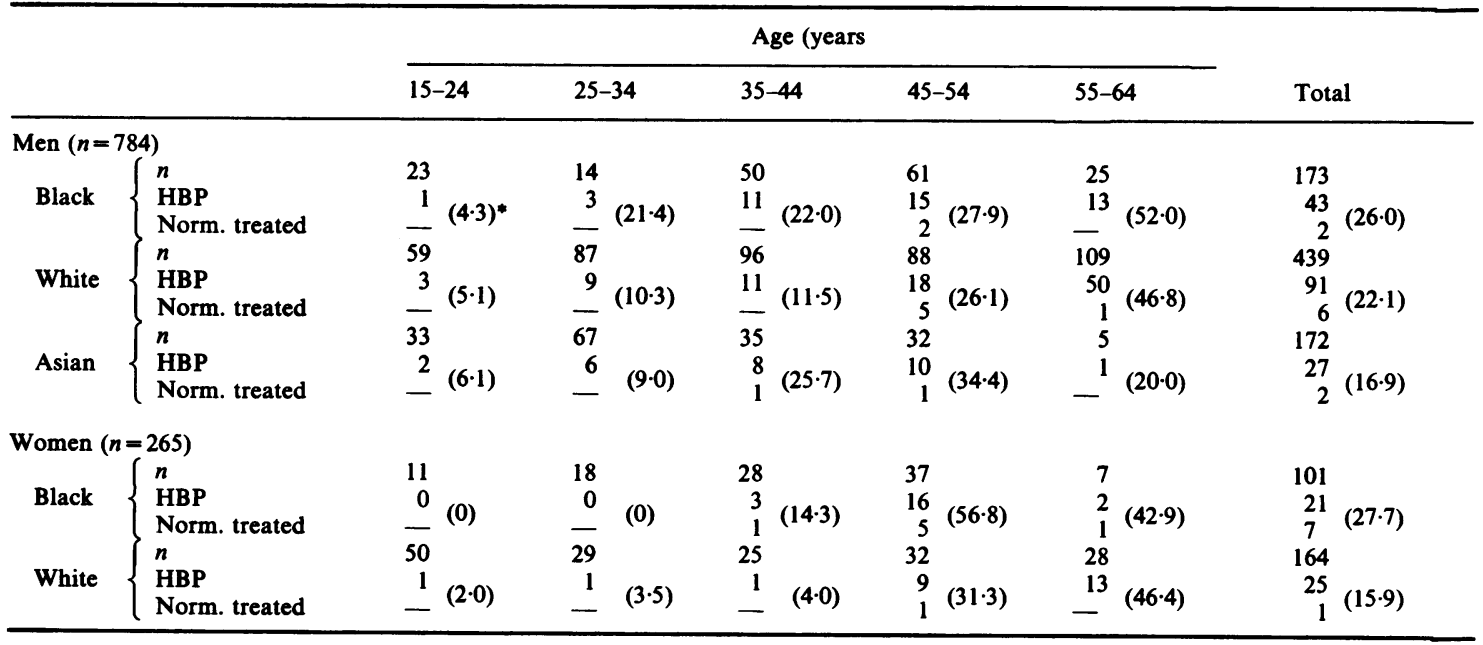

*Figures in parentheses are percentages of total subjects $(n)$ with BP $>160 \mathrm{mmHg}$ systolic or $>95 \mathrm{mmHg}$ diastolic (HBP) and/or below this level on treatment (Norm. treated) (WHO criteria). 
but Asian men, aged 25-34 years, had lower systolic pressures and Asian men, aged 35-44 years, had higher diastolic pressures than either the black or white subjects. Analysis or covariance using age as the covariate showed that, overall, Asians had significantly lower systolic pressures than either black or white men $\left[\mathrm{F}_{(1,772)}=4.65 ; P<0.05\right]$, but also higher diastolic pressures than the other ethnic groups $\left[\mathrm{F}_{(1,772)}=4.2 ; P<0.05\right]$. Pulse pressures among Asian men were smaller. From ages 25 to 54 years, black women had consistently higher systolic pressures than whites, and from 35-64 years, higher diastolic levels (Fig. 2). These systolic pressures are not significantly different by analysis of covariance with age $\left[F_{(1,281)}=0.54 ; N S\right]$ but for diastolic pressures the differences are highly significant $\left[\mathrm{F}_{(1,281)}=7 \cdot 82\right.$; $P<0.01]$. However, addition of body mass index as a second covariate revealed these diastolic differences to be entirely dependent on the much greater fatness of West Indian women $\left[F_{(1,265)}=0 \cdot 24\right]$. This result is in keeping with the hypothesis that body mass is a more major determinant, even than age, of diastolic pressure than systolic pressure.

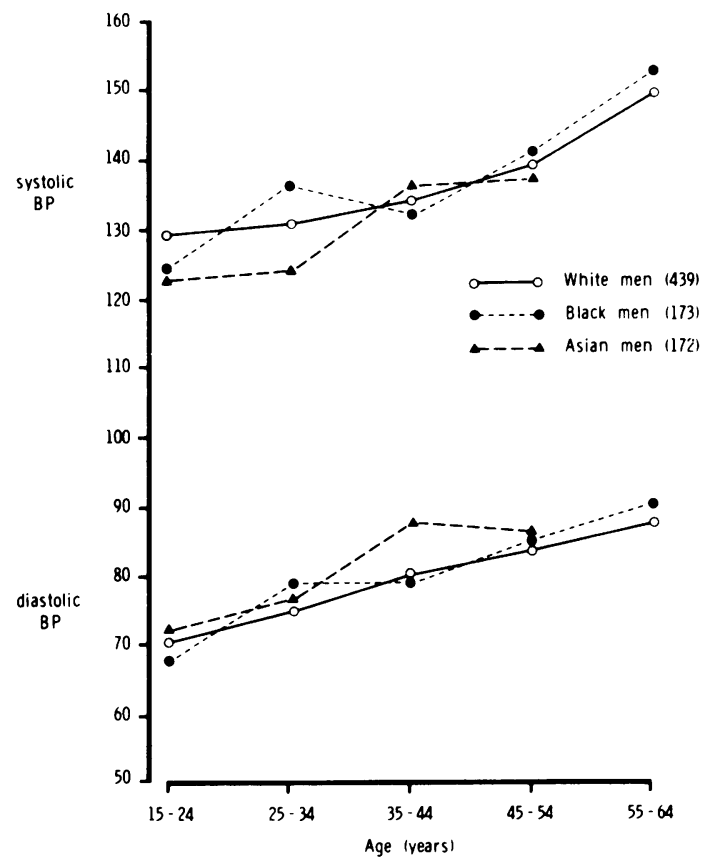

FIG. 1. Mean systolic and diastolic blood pressure in male black white $\bigcirc$ and Asian $\Delta$ factory workers.

\section{Discussion}

This study has found that male black West Indian factory workers in Birmingham do not have higher blood pressures on average than similarly aged whites or Asians. This finding is contrary to the initial

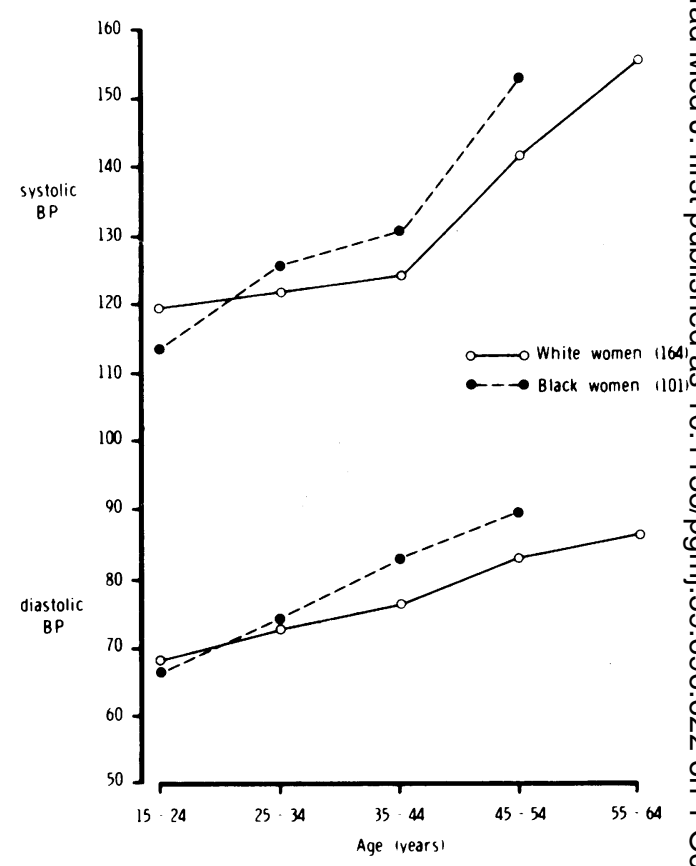

FIG. 2. Mean systolic and diastolic blood pressures in female bla $\checkmark$ and white $\bigcirc$ factory workers.

hypothesis and to widely held clinical impressionge These results are not due to medical screening excluding hypertensives before starting employmen? as none of the factories studied operated such policy. The only selection criterion was that employ ees were visibly fit enough to work. Possibly, unent? ployed or unfit black men might have had highe pressures causing morbidity precluding employmen this seems unlikely in the age-range we studied. A important point in this study is that almost at examinees were from social classes 3 to 5 , and thus. the ethnic groups were well matched.

The rise in average blood pressure with increasing age and hence the increase in arbitrary hypertensio rates, conforms to the usual pattern seen in developed societies but is markedly different from the trend found among rural Africans, where hypertension unusual (Akinkugbe, 1972).

Previous reports from Britain have included onlfy small numbers of subjects from the ethnic minority groups. In the Northwick Park Heart Study (Meade et al., 1978), 48 day-shift and 38 of the night-shitio male workers and 55 female day workers were blacle Blood pressures were significantly higher in blackes than whites only in the day-shift, with no significant difference among the night workers. The mean ages of both groups for the day-shift were similar, bup 
range and standard deviations were not reported. Social class was also unevenly matched. Sever et al. (1978) found higher blood pressures in blacks than age-matched whites, but these subjects were volunteers combining people of West Indian and of African origin and all had been previously included in the Northwick Park study. The current study includes West Indians only and is larger than any other yet conducted in Britain.

Black women over 35 years did have higher mean blood pressures than white women but, using analysis of covariance, this is accounted for by the higher prevalence of obesity, even though large cuffs were employed on obese arms. More black than white women were on antihypertensive treatment $(17 \% v$. 4\%) and were controlled (Table 1).

Little data are available on blood pressure distribution among Asians in Britain. A community survey of Asian women in Southall, West London (Keil et al., 1980) recorded the overall prevalence of hypertension as $16 \%$, which was similar to that for local white women. No data seem to have been reported for Asian men. Epidemiologically sound studies from rural and urban India have shown a relatively low prevalence of hypertension when compared with western societies (Padmavati and Gupta, 1959). The finding here of higher diastolic pressures and lower pulse pressures among Asian men is thus of great interest and requires confirmation.

The lack of a black/white blood pressure difference in this study is contrary to the United States experience, where it has been firmly established that black adults have higher pressures at all ages than whites (Comstock, 1957; Cassel, 1971; Gillum and Grant, 1982). The Chicago industry report, although more extensive, is the most directly comparable to this study, being factory based, but using a single (conventional) blood pressure reading. The 20048 white and 2077 black volunteer subjects screened only represented some $50 \%$ of the available workforce, whereas nearly $80 \%$ were screened here. However, the size effect in Chicago probably swamps any bias due to selective sampling (Stamler et al., 1975).

There are 2 other possible reasons for the different outcome in this study compared to the U.S. Firstly, social class was closely matched here; in the U.S. when socioeconomic variations in screened populations are minimized, racial differences have been markedly reduced or abolished (Langford, 1981; Harburg et al., 1973).

Secondly, black people from the West Indies who migrated to Britain may have genuinely different blood pressures from blacks longer resident in the U.S. Indeed, Miall detected only a slight excess of high blood pressure in Jamaica compared to his readings taken among white subjects in Wales (Miall and Cochrane, 1961), although temperature differences may have reduced Jamaican values.

These results suggest that despite clinical impressions, average blood pressures are no higher in black than in white subjects. However, they do not exclude different mechanisms of patho-physiology in the development of hypertension in the different ethnic groups. A new finding requiring confirmation is the higher diastolic but lower pulse pressures recorded among Asian men.

\section{Acknowledgments}

We are grateful to the management and workforce of the following factories in Birmingham for helping us with this study: Delta Wires Limited, GKN Fasteners Limited, Blue Circle Cement Limited, R.G. Brown Limited, Stevens \& Bullivant Co. Ltd., The Birmingham Box Co. Ltd., T.I. Sturmey Archer Ltd., Brockhouse District Steel Co. Ltd., Metal Finishers Ltd. and Tongue and Wills Ltd.

This research project was supported by grants from Sandoz Limited, ICI Pharmaceuticals Limited, Glaxo Limited and the West Midlands Regional Research Committee.

\section{References}

AKINKUGBE, O.O. (1972) High blood pressure in Africans. ChurchillLivingstone, Edinburgh.

CASSEL, J.C. (1971) Summary of major findings of the Evans County cardiovascular studies. Archives of Internal Medicine, 128, 887.

Comstock, G.W. (1957) An epidemiologic study of blood pressure levels in a biracial community in the Southern United States. American Journal of Hygiene, 65, 271.

Cruickshank, J.K. Beevers, D.G., Osbourne, V.L., Haynes, R.A., CoRletT, J.C. \& SelbY, S. (1980) Heart attack, stroke, diabetes and hypertension in West Indians, Asians and whites in Birmingham, England. British Medical Journal, 281, 1108.

GILlUM, R.F. \& GRANT, C.T. (1982) Coronary heart disease in black populations. II Risk factors. American Heart Journal, 104, 85.

harburg, E., Erfurt, J.C., Chape, C., Hammerstein, L., Schull, W.J. \& SCHORK, M.A. (1973) Socioecological stressor areas and black-white blood pressure: Detroit. Journal of Chronic Disease, 26, 595 .

KeIL, J.E., WEINRICH, M.C., KEIL, B.W., BRITT, R.P. \& Hollis, Y. (1980) Hypertension in a population sample of female Punjabi Indians in Southall. Journal of Epidemiology and Community Health, 34, 45.

LANGFORD, H. (1981) Is blood pressure different in black people? Postgraduate Medical Journal, 57, 749.

MARMOT, M.G., ADELSTEIN, A.M. \& Bulusu, L. (1981) Cardiovascular mortality among immigrants to England and Wales. Postgraduate Medical Journal, 57, 760.

Meade, T.W., Brozovic, M., Chakraborti, R., Haines, A.P., NORTH, W.R.S. \& STIRLING, Y. (1978) Ethnic group comparisons of variables associated with ischaemic heart disease. British Heart Journal, 40, 789.

Miall, W.E. \& Cochrane, A.L. (1961) Distribution of arterial pressure in Wales and Jamaica. Pathologia et microbiologia, 24, 690.

Padmavati, S. \& GuPta, S. (1959) Blood pressure studies in rural and urban groups in Delhi. Circulation, 29, 395.

Pedoe, H.T., Clayton, D., Morris, J.N., Brigden, W. \& MCDoNALD, L. (1975) Coronary heart attacks in East London. Lancet, ii, 833.

Sever, P.S., Peart, W.S., Meade, T.W., Davies, I.E., Gordon, D. \& TUNBRIDGE, R.D.G. (1978) Are racial differences in essential 
hypertension due to different pathogenetic mechanisms? Clinical Science, 55, 383s.

STAMLER, J., RHOMbERG, P., SCHOENBERGER, J.A., SHEKELlE, R.B., Dyer, A., Shekelle, S., Stamler, R. \& WARremaker, J. (1975)
Multivariate analysis of the relationship of (six and) variables to blood pressure. Journal of Chronic Disease, 28, 52 WHO TECHNICAL REPORTS (1979) Arterial hypertension. Gen\&a 1979. 